\title{
O voo dos pássaros egressos da Licenciatura em Educação do Campo da UFRGS: desafios e possibilidades na formação de professores de Ciências da Natureza
}

\footnotetext{
(iD) Antonio Marcos Teixeira Dalmolin ${ }^{1}$, iD Marilisa Bialvo Hoffmann ${ }^{2}$, (iD) Saul Benhur Schirmer ${ }^{3}$ 1, 2, 3 Universidade Federal do Rio Grande do Sul - UFRGS. Departamento de Ensino e Currículo / Faculdade de Educação. Prédio 12201, Avenida Paulo Gama, 110, Farroupilha. Porto Alegre - RS. Brasil.
}

Autor para correspondência/Author for correspondence: antoniodalmolin@gmail.com

RESUMO. O presente artigo apresenta um estudo sobre a atuação de egressos do curso de Licenciatura em Educação do Campo: Ciências da Natureza da Universidade Federal do Rio Grande do Sul (LEDOC/UFRGS), campus Porto Alegre. Como problema de pesquisa se estabeleceu o seguinte questionamento: Como voam os pássaros egressos e egressas da LEDOC/UFRGS campus Porto Alegre? O objetivo foi analisar, a partir dos dados de acompanhamento do curso, a atuação dos egressos e egressas, bem como refletir sobre os desafios e potencialidades da formação de professores e professoras de ciências do campo, a partir das entrevistas realizadas. A pesquisa é qualitativa, do tipo estudo de caso e foram utilizadas entrevistas semiestruturadas, como instrumento de investigação. $\mathrm{Na}$ análise das transcrições foi utilizada a Análise Textual Discursiva (ATD). Os resultados foram discutidos a partir da categoria, definida a priori, Tríade Campo - Política Pública - Educação nos movimentos de bater as asas. Ao final, consideramos que os egressos e egressas entrevistados, após o curso, ressignificaram suas formas de ler e intervir em seus territórios.

Palavras-chave: egressos, formação de professores, educação do campo, ciências da natureza. 


\title{
The flight of the graduate birds from the UFRGS Rural Education Course: challenges and possibilities in teacher training in Natural Sciences
}

\begin{abstract}
This article presents a study on the performance of graduates of the Licentiate's in Rural Education: Nature Sciences of the Federal University of Rio Grande do Sul (LEDOC/UFRGS), Porto Alegre campus. As a research problem, the following question was established: How do birds from LEDOC/UFRGS campus Porto Alegre fly? The objective was to analyze, from the course monitoring data, the performance of graduates, as well as to reflect on the challenges and potential of teacher education of natural sciences in rural education, based on the interviews carried out. The research is qualitative, of the case study type and semi-structured interviews were used as a research instrument. The Discursive Textual Analysis (DTA) was used to analyze the transcripts. The results were discussed from the category, defined a priori, Triad: Rural - Public Policy - Education in flapping movements. In the end, we consider that the graduates interviewed, after the course, gave new meanings to their ways of reading and intervening in their territories.
\end{abstract}

Keywords: graduates, teacher training, rural education, natural sciences. 


\section{Vuelo de pájaros graduados en Educación Rural de la UFRGS: retos y posibilidades en la formación de profesores de Ciencias de la Natureza}

RESUMEN. Este artículo presenta un estudio sobre el desempeño de los egresados de la Licenciatura en Educación Rural: Ciencias de la Naturaleza de la Universidad Federal de Rio Grande do Sul (LEDOC/UFRGS), campus de Porto Alegre. Como problema de investigación se estableció la siguiente pregunta: ¿Cómo vuelan los pájaros de la LEDOC/UFRGS en Porto Alegre? El objetivo fue analizar, a partir de los datos del curso, el desempeño de los egresados, así como reflexionar sobre los desafíos y potencialidades de la formación de profesores de ciencias en Educación Rural, a partir de las entrevistas realizadas. La investigación es cualitativa, tipo estudio de caso y se utilizaron entrevistas semiestructuradas como instrumento de investigación. Se utilizó Análisis Textual Discursivo (ATD) para analizar las transcripciones. Los resultados fueron discutidos desde la categoría, definida a priori, Tríada: Rural - Política Pública - Educación en movimiento de vuelo. Al final, consideramos que los egresados entrevistados, tras el curso, redefinieron sus formas de leer e intervenir en sus territorios.

Palabras clave: graduados, formación de profesores, educación rural, ciencias de la Naturaleza. 


\section{Sobre $\mathrm{o}$ ar que sustenta $\mathrm{o}$ voo}

O Brasil, em função de suas características geográficas, do montante de terras agricultáveis, dos processos históricos de constituição de seu território, se consolidou como um país essencialmente agrícola, mas também de intensa concentração de terras pela elite econômica, aliada à exploração de trabalhadores escravizados ou não. Na esteira da construção de alternativas de geração de renda, a partir dos anos de 1980, intensificaram os movimentos de luta pela reforma agrária, ou seja, por políticas públicas voltadas à distribuição de terras denominadas improdutivas, sem destinação a nenhum fim, para a produção de alimentos e geração de renda àqueles que não eram "herdeiros de capitanias hereditárias".

Com um país de extensão continental, com grandes áreas denominadas rurais, aliada à solidificação do preceito de educação como direito social e dever do Estado Brasileiro, a ser provida por seus entes federativos, segundo a Constituição Federal de 1988, os movimentos sociais do campo incluíram, em sua pauta política, a oferta de uma educação contextualizada para as pessoas que vivem e trabalham no campo. Segundo Caldart (2008, p. 70) a "materialidade de origem (ou de raiz) da Educação do Campo exige que ela seja pensada/trabalhada sempre na tríade: Campo - Política Pública - Educação". Assim, o movimento de luta por Educação do Campo, coloca em pauta uma educação como política pública do Estado Brasileiro, que dialoga com os contextos vividos no campo. Para Arroyo, Caldart e Molina,

... a identidade desse movimento por uma educação do campo é a luta do povo do campo por políticas públicas que garantam $\mathrm{o}$ seu direito à educação e a uma educação que seja no e do campo. No: o povo tem direito a ser educado no lugar onde vive; Do: o povo tem direito a uma educação pensada desde o seu lugar e com a sua participação, vinculada à sua cultura e às suas necessidades humanas e sociais (2011, p. 149150).

Em termos da compreensão semântica do termo "campo", nos apoiamos no texto legal, nos termos do Decreto $n^{0} 7352 / 2010$, que dispõe sobre a política de Educação do Campo e o Programa Nacional de Educação na Reforma Agrária - PRONERA, definindo populações e escola do campo como:

I - Populações do campo: os agricultores familiares, os extrativistas, os pescadores artesanais, os ribeirinhos, os assentados e acampados da reforma agrária, os trabalhadores assalariados rurais, os quilombolas, os caiçaras, os povos da floresta, os caboclos e outros que produzam suas condições 
materiais de existência a partir do trabalho no meio rural; e,

II - Escola do campo: aquela situada em área rural, conforme definida pela Fundação Instituto Brasileiro de Geografia e Estatística - IBGE, ou aquela situada em área urbana, desde que atenda predominantemente a populações do campo (Decreto $\mathrm{n}^{\circ}$ 7352, 2010).

O Campo, neste sentido, é um lugar diverso e plural composto de diferentes pessoas, contextos e culturas, unidas pelo ideal de produção de vida nesses espaçostempo. Para Arroyo, Caldart e Molina (2011, p. 08), o principal desafio da Educação do Campo é "entender os processos educativos na diversidade de dimensões que os constituem como processos sociais, políticos e culturais, formadores do ser humano e da própria sociedade".

Desta maneira, segundo Fernandes, Cerioli e Caldart (2004, p. 22), destacou-se como um dos marcos históricos do debate sobre educação do campo, a realização da "Primeira Conferência Nacional: por uma Educação Básica do Campo”, em 1998. Conforme Mançano e Tarlau (2017) nesse mesmo ano é lançado o PRONERA constituindo a primeira política educacional voltada para o desenvolvimento dos territórios de agricultura camponesa no Brasil. Com o avanço do debate, de intensa participação dos movimentos sociais do campo, foram sistematizadas proposições em torno da formação docente, entendendo-a como uma das frentes importantes de construção, ou seja, uma Educação do Campo contextualizada e articulada com seu espaço-tempo de vida e trabalho, requer investimento na formação inicial de docentes para atuação no campo. Assim, em 2007, nascem as primeiras Licenciaturas em Educação do Campo (LEDOC), com quatro cursos em projetopiloto, como política pública do Ministério da Educação, conforme historicizado por Molina (2017a, p. 03).

Após a criação de outros cursos, no ano de 2012 houve significativo crescimento do número de LEDOC, conforme Molina (2017a). Segundo Dalmolin e Garcia (2020, p. 4), a criação de mais de quarenta LEDOC, em todas as regiões do Brasil, pelo Edital de Seleção No 02/2012 SESU/SETEC/SECADI/MEC, criou mais de "600 novas vagas docentes do Magistério Superior e mais de 120 servidores técnicos administrativos em educação nas Universidades Federais", o que implica em fortalecer o campo de pesquisa e formação docente em educação do campo. De acordo com Melzer, Brick e Hoffmann (2021), a partir desta trajetória de construção da política, constituiu-se o espaço da Licenciatura em Educação do Campo tendo, atualmente, 59 cursos ativos 
em todo o País. Os mesmos autores ressaltam, nos editais do Programa de Apoio à Formação Superior em Licenciatura em Educação do Campo (PROCAMPO), “a vinculação da constituição dos projetos de cursos com a área de Ciências da Natureza como prioritária. Essa prioridade se estabelece a partir do déficit de professores formados nas áreas das Ciências da Natureza no Brasil" (p. 184). Outro ponto evidenciado no trabalho de Melzer, Brick e Hoffmann (2021) é a composição das LEDOC do sul do Brasil:

Analisando os projetos dos cursos e os dados do Censo da Educação Superior (INEP), percebe-se que dez cursos têm como objetivo a formação de professores em Ciências da Natureza. Destes, sete continuam em atividade e os outros três estão em processo de extinção ou já foram descontinuados em suas respectivas instituições. ... Quando olhamos para a composição docente desses sete cursos, evidenciamos a consolidação de um coletivo de professores que ensinam Ciências da Natureza e Matemática na compreensão da Educação do Campo (Melzer, Brick \& Hoffmann, 2021, p. 185).

No contexto do Estado do Rio Grande do Sul (RS), contamos com cinco
LEDOC em funcionamento, todas com formação na área de Ciências da Natureza (Figura 1). São elas: 1) Licenciatura em Educação do Campo: ênfase em Ciências da Natureza e Ciências Agrárias, da Fundação Universidade Federal do Rio Grande (FURG)/campus São Lourenço do Sul; 2) Licenciatura em Educação do Campo - Ciências da Natureza, da Universidade Federal da Fronteira Sul (UFFS)/campus Erechim; 3) Curso de Educação do Campo - Licenciatura, da Universidade Federal do Pampa (UNIPAMPA)/ campus Dom Pedrito; 4) Licenciatura em Educação do Campo: Ciências da Natureza, da Universidade Federal do Rio Grande do Sul (UFRGS)/campus Porto Alegre; e 5) Licenciatura em Educação do Campo: Ciências da Natureza, da Universidade Federal do Rio Grande do Sul (UFRGS)/campus Litoral Norte. 


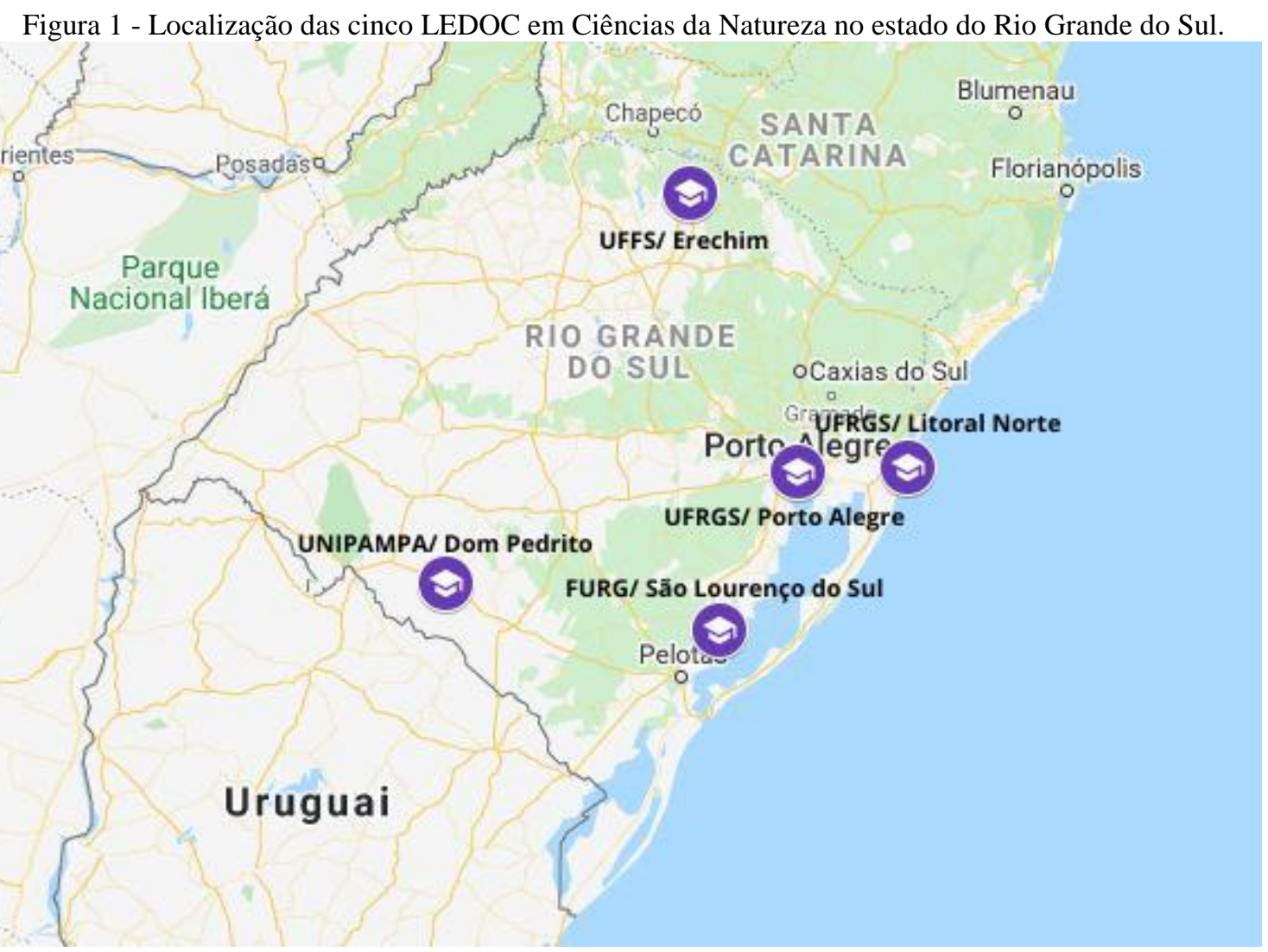

Fonte: Elaborada pelos autores, 2021.

Dentre estes cursos implementados, estão as duas Licenciaturas em Educação do Campo: Ciências da Natureza da Universidade Federal do Rio Grande do Sul (UFRGS), uma sediada na Faculdade de Educação (FACED) em parceria com a Faculdade de Agronomia (FAGRO), na cidade de Porto Alegre, Rio Grande do Sul (RS) e a outra LEDOC no campus Litoral Norte, na cidade de Tramandaí - RS. O contexto da presente investigação é a LEDOC da FACED-FAGRO/UFRGS, por nossa vivência enquanto educadores do curso. Este curso atende a uma área de abrangência de setenta municípios, compreendendo a Região Metropolitana de Porto Alegre, Serra Gaúcha, Vale do Caí, Vale do Rio dos Sinos, Vale do Taquari, Vale do Paranhana, Encosta da Serra, Centro Sul, Vale do Rio Pardo e Jacuí Centro (classificações de acordo com os Conselhos Regionais de Desenvolvimento - COREDEs, 2021). As referidas localizações podem ser verificadas no mapa da Figura 2. 
Figura 2: Área de abrangência da LEDOC - UFRGS campus Porto Alegre.

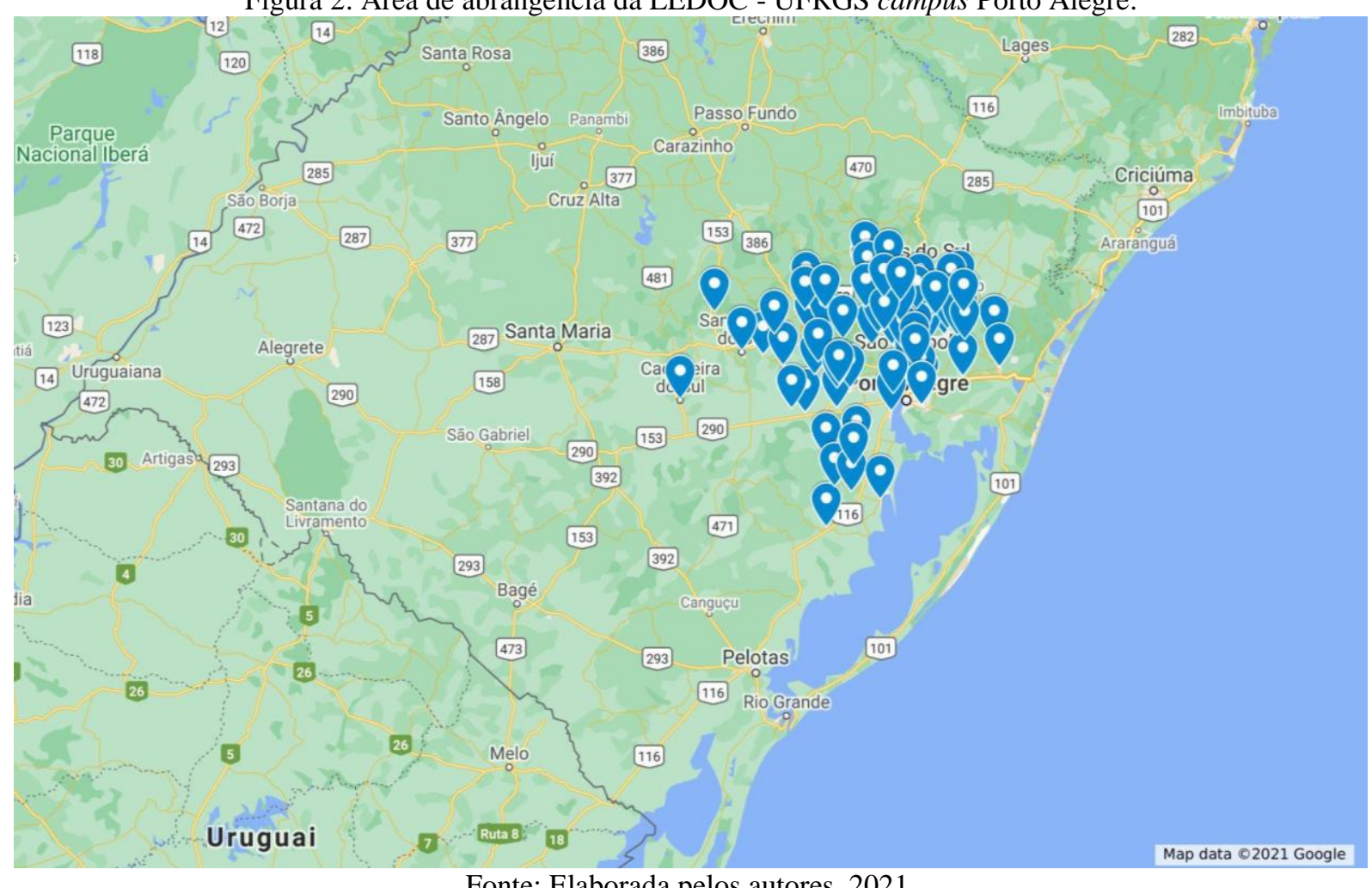

Fonte: Elaborada pelos autores, 2021.

A metáfora do voo dos pássaros foi inspirada no trabalho de doutoramento de Dalmolin (2020), que se apoiou em Freire (1995), para pesquisar sobre o diálogo da Educação do Campo com as Ciências da Natureza, à sombra do Jacarandá (Nome Popular: Jacarandá-mimoso - Nome Científico: Jacaranda mimosifolia D. Don.). A Faculdade de Educação da UFRGS é rodeada (Figura 3) por árvores de Jacarandá-mimoso que acolheram os pássaros da LEDOC, que metaforicamente, representam os egressos e egressas, que pousaram a sombra do Jacarandá, durante o tempo de suas formações como educadores e educadoras do campo. A LEDOC lhes permitiu voar dialeticamente entre o Tempo Universidade e o Tempo Comunidade, no regime de alternância pedagógica do curso. 
Figura 3 - Jacarandá-mimoso localizado na Faculdade de Educação da UFRGS, em Porto Alegre.

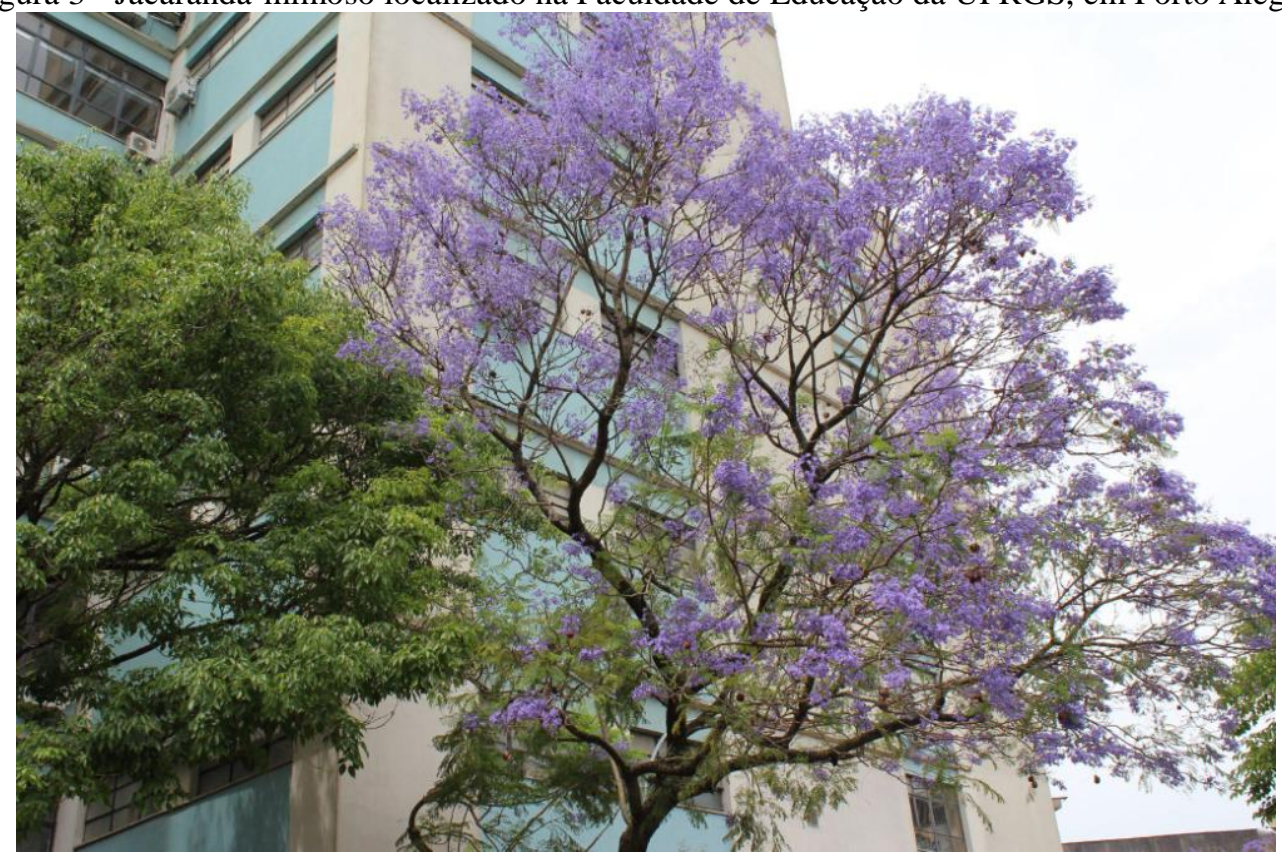

Fonte: Arquivo pessoal dos autores, 2019.

Ao vivenciar a formação docente na LEDOC, os pássaros-estudantes tiveram a oportunidade de conhecer mais sobre o ar que pode sustentar futuros voos, desafios, na condição de educadores e educadoras do campo, egressas da UFRGS. Nesse contexto, nos movemos em direção ao seguinte problema de pesquisa: Como voam os pássaros egressos e egressas da LEDOC/UFRGS campus Porto Alegre? Em termos de objetivos, nos propomos a analisar a atuação dos egressos e egressas da LEDOC/UFRGS campus Porto Alegre, a partir dos dados de acompanhamento do curso, bem como refletir, a partir das entrevistas realizadas com os egressos e egressas, sobre os desafios e potencialidades da formação de professores e professoras de ciências do campo, na região de abrangência do curso.

Os nossos movimentos em responder ao problema de pesquisa perpassam, no primeiro momento, pela identificação de revoadas pelo Brasil em uma revisão de pesquisas sobre egressos em licenciaturas em educação do Campo. No segundo momento são analisados os voos dos pássaros egressos da LEDOC FACEDFAGRO/UFRGS onde é apresentada uma análise em termos da tríade Campo Política Pública - Educação, proposta por Caldart (2008), dos desafios e possibilidades relacionados à atuação dos/as egressos/as da LEDOC/UFRGS.

O debate sobre o ar que sustenta o voo apresentou nossos movimentos introdutórios ao tema deste escrito, nos 
conduziu à identificação da questão de pesquisa, para caracterizar nosso ponto de observação, qual seja, a sombra do Jacarandá-mimoso da FACED/UFRGS. A seguir é apresentada a caminhada metodológica a fim de responder aos objetivos do trabalho.

\section{Análise de percursos}

Os pássaros egressos e egressas da LEDOC/UFRGS voaram da sombra do Jacarandá após suas colações de grau, para trilhar outros caminhos em suas vidas. Nesse sentido, sob a sombra do Jacarandámimoso, nos movemos à sistematização dos encaminhamentos metodológicos para analisar os voos dos pássaros egressos. Assim, a presente pesquisa foi classificada como qualitativa segundo Moraes \& Galiazzi (2016, p. 33), pois objetiva a compreensão profunda dos fenômenos, sem a pretensão de "testar hipóteses para comprová-las ou refutá-las ao final da pesquisa".

O método de pesquisa utilizado foi o estudo de caso, segundo Stake (1998). Para o autor, o estudo de caso constitui um método de pesquisa que estuda a particularidade e a complexidade de um caso singular. Segundo Stake, esta pesquisa se enquadra como um estudo de caso do tipo instrumental, pois esse caso, além de possibilitar a compreensão de si, permite a problematização de questões mais amplas (Stake, 1998, p. 11). Nesse contexto, o caso abarca, em complexidade e particularidade, elementos da formação de egressos e egressas na LEDOC da UFRGS, na área de Ciências da Natureza.

Como instrumento da pesquisa foram utilizadas entrevistas semiestruturadas e participaram da pesquisa três egressos e egressas da primeira turma de educadores e educadoras do campo da FACEDFAGRO/UFRGS, com colação de grau no ano de 2018, no campus Porto Alegre. Foram observados os critérios de conveniência e disponibilidade dos participantes na composição do tamanho do grupo a ser entrevistado.

\section{A LEDOC FACED-FAGRO/UFRGS} formou 43 licenciados e licenciadas em Educação do Campo: Ciências da Natureza, sendo 6 na primeira turma (2018), 15 na segunda turma (2019) e 22, até o momento, na terceira turma (2020). A opção por entrevistar apenas egressos da primeira turma ocorreu em função de que na ocasião de registro do projeto de pesquisa, era a única turma com egressos. Entendemos que três entrevistas têm potencial para responder aos objetivos da pesquisa

As entrevistas foram realizadas de 27 de agosto a 25 de setembro de 2019 e os aspectos éticos e legais foram cumpridos. 
O projeto foi aprovado pelo Comitê de Ética em Pesquisa da UFRGS, via Plataforma Brasil, sob o CAAE 16100819.9.0000.5347. Os participantes, maiores de 18 anos, aceitaram participar da pesquisa mediante a assinatura do Termo de Consentimento Livre e Esclarecido. Seus nomes foram substituídos, independentemente de sexo ou gênero, por nomes de pássaros da fauna brasileira, quais sejam: Cardeal - Nome científico: Paroaria coronata; Caturrita - Nome científico: Myiopsitta monachus; e Joãode-barro - Nome científico: Furnarius rufus.

O roteiro da entrevista semiestruturada foi composto por 19 questões que, por exemplo, abordaram a relação pessoal e profissional dos participantes com o campo, bem como sobre temas caros à LEDOC como a Alternância pedagógica, a interdisciplinaridade e a formação por área de conhecimento. As entrevistas foram presenciais, com duração média de 50 minutos e as falas foram captadas em um gravador de voz. As falas foram transcritas, a transcrição foi lida e aprovada pelos participantes. Após, foram analisadas na pesquisa por meio da Análise Textual Discursiva (ATD) de Moraes e Galiazzi (2016).
A ATD é a técnica de análise das transcrições das entrevistas, composta de um ciclo de análise com 3 etapas: unitarização, categorização e comunicação. A unitarização consiste no momento de desconstrução das falas transcritas, por meio da leitura e identificação das unidades de análise. Essas, consistem em 81 fragmentos retirados dos textos, que foram codificados com o nome do pássaro, seguido de um número, que ordena as unidades extraídas das falas dos participantes. Elas dialogam com os objetivos da pesquisa e os referenciais dos pesquisadores, no processo de compreensão dos objetos da investigação.

A categorização é a segunda etapa do ciclo, na qual as unidades de análise se organizam formando as categorias. Nessa pesquisa, a opção foi pela definição de uma única categoria antes da análise, ou seja, uma categorização a priori. A categoria definida foi a "tríade Campo Política Pública - Educação nos movimentos de bater as asas". A última etapa do ciclo é a comunicação, momento de construção de novas sínteses, a partir das unidades de análise e a categoria definida na pesquisa. 
Outras revoadas em pindorama: egressos e egressas

A partir das experiências-piloto a Educação do Campo, tão esquecida nas investigações educacionais, ao longo de muitos anos (Arroyo, 1998), passa a ocupar maior destaque nas pesquisas da área de educação. Conforme Souza (2020) e Andrade et al. (2019) é possível perceber que o aumento no interesse das pesquisas se dá a partir de datas que coincidem com editais do PRONERA. Nesse sentido, junto à criação das LEDOC nas universidades brasileiras surgem grandes impactos ainda a serem desvelados pela própria pesquisa acadêmica.

Frente aos desafios impostos com a implementação das Licenciaturas em Educação do Campo nas universidades públicas brasileiras, tais como: um novo projeto de escola do/no campo, uma formação comprometida organicamente com as comunidades e movimentos sociais, a formação de um novo nível de consciência em relação à atuação do agronegócio nos territórios, a valorização da agroecologia e da agricultura familiar camponesa, entre outros, faz-se necessário, neste momento, uma avaliação de como estão atuando os egressos e egressas destes cursos. Desta forma, constitui-se como potencial tema de estudo o mapeamento de possíveis impactos das LEDOC em suas regiões de abrangência, tanto nos espaços escolares como não-escolares das comunidades.

Neste contexto, Molina \& Pereira (2021) realizaram uma pesquisa acerca da produção científica no âmbito da pósgraduação, que aborda a atuação dos egressos das LEDOC brasileiras, analisando a maneira como os egressos estão atuando em suas comunidades, a fim de compreender em que medida o perfil de educador proposto pelo curso se materializa na ação desses egressos nas Escolas do Campo e nos territórios rurais dos quais se originam (p. 141). Os autores identificaram vinte e cinco trabalhos apresentados, em nível de pós-graduação Stricto sensu, que abordam a questão da atuação dos licenciados em seus territórios, sendo dez teses e quinze dissertações. Após revisão destes trabalhos, concluíram que há relativa inserção dos egressos nas áreas de conhecimento em que foram formados, mas também muitos casos em que ocorre o contrário, com vários atuando em escolas do campo, porém nos Anos Iniciais do Ensino Fundamental. Da mesma forma, os dados analisados pelos autores demonstram que os egressos têm tentado inserir mudanças nos modos de trabalho e métodos de organização escolar nas instituições em que atuam, embora 
fiquem claros os limites dessa atuação, tais como:

Há vários fatores que podem contribuir para a compreensão desse limite, que vão desde a rigidez das redes públicas, presas a estruturas de contratação docente rígidas e disciplinares, até os limites dos próprios docentes formadores das universidades que atuam nas LEdoCs, de compreenderem e exercerem de fato uma formação a partir das áreas de conhecimento nas Licenciaturas em Educação do Campo. (Molina \& Pereira, 2021, p. 154).

A investigação realizada por Ângelo (2019) mostra que a superação destes limites possivelmente se dá mais em contextos nos quais os egressos das LEDOC estejam engajados em movimentos sociais e sindicais do campo. A autora, ao realizar uma análise das práticas sociais de egressas de uma LEDOC, considera que as lutas que estas enfrentam no campo educacional não estão desvinculadas das demais, pois, ao se pautar um outro projeto de campo que não o hegemônico, ficam claras as contradições e as forças atuantes envolvidas nos processos educativos. Do mesmo modo, a autora pontua que as parcerias entre a LEDOC e os movimentos sociais podem ter reflexos muito positivos nos processos de mudança, nos territórios de origem dos cursistas, constituindo uma força de mobilização e engajamento.
Britto (2017), em sua tese de doutoramento, analisou a contribuição dos egressos para os princípios formativos desenvolvidos em uma LEDOC e a contribuição dos mesmos para a Política Pública de Formação de Educadores do Campo no Brasil, no sentido de compreender a formação na perspectiva da práxis criativo-revolucionária. Concluiu que os egressos do curso em questão incorporaram os princípios do Movimento da Educação do Campo, tais como: a Autoorganização dos estudantes; o Trabalho como princípio educativo; a Pesquisa como princípio formativo; a Interdisciplinaridade; a Mística; a Autogestão; o Trabalho Coletivo; o Currículo ligado à realidade; e a Relação teoria e prática como princípio de formação. O autor aponta que a atuação dos egressos tem se traduzido em contribuições importantes aos seus locais de atuação profissional.

A tese de Silva (2017) investigou como se dá a interdisciplinaridade na prática educativa dos egressos da LEDOC do Instituto Federal do Pará - Campus Castanhal. A investigação foi feita junto às escolas de atuação dos egressos e contou, em termos de instrumentos metodológicos, com entrevistas e observações. Conforme a pesquisadora, os educadores conseguem realizar uma educação contextualizada, e 
em alguns momentos relacionam os conteúdos de diversas disciplinas em suas aulas, ainda que em práticas isoladas. Para ela, as escolas propiciam poucos momentos coletivos de planejamentos, reuniões e avaliações, ou mesmo pela disciplinaridade do currículo.

Além dessas investigações, há diversas dissertações de mestrado que realizam investigações com egressos das LEDOC. É importante destacar os grandes desafios enfrentados e o papel protagonista que assumem esses egressos, ainda que na adversidade do contexto vivido pela educação brasileira. Nesse sentido, também estão imersos os egressos e egressas da LEDOC/UFRGS, que têm a análise de seus voos apresentados na seção seguinte.

Tríade Campo - Política Pública Educação nos movimentos de bater as asas
Os egressos e egressas da LEDOC/UFRGS, após vivenciar a acolhedora sombra do Jacarandá-mimoso da FACED, voaram para além dela, alçaram novos voos, com suas novas asas, significadas e ressignificadas no processo de tornar-se educador e educadora do campo, na área de Ciências da Natureza. Na visão de Caldart (2008, p. 70), a Educação do Campo deve ser pensada/trabalhada sempre na tríade: Campo - Política Pública - Educação (ilustrado na figura 4), por exigência da materialidade de origem da Educação do Campo. Ou seja, a Educação do Campo nasce em uma disputa de projetos de campo e, neste sentido, toma partido por políticas públicas que têm forma, conteúdo e sujeitos bem definidos, bem como forte crítica à educação pensada em si mesma ou em abstrato.

Figura 4 - A atuação dos egressos na tríade Campo-Política Pública-Educação.

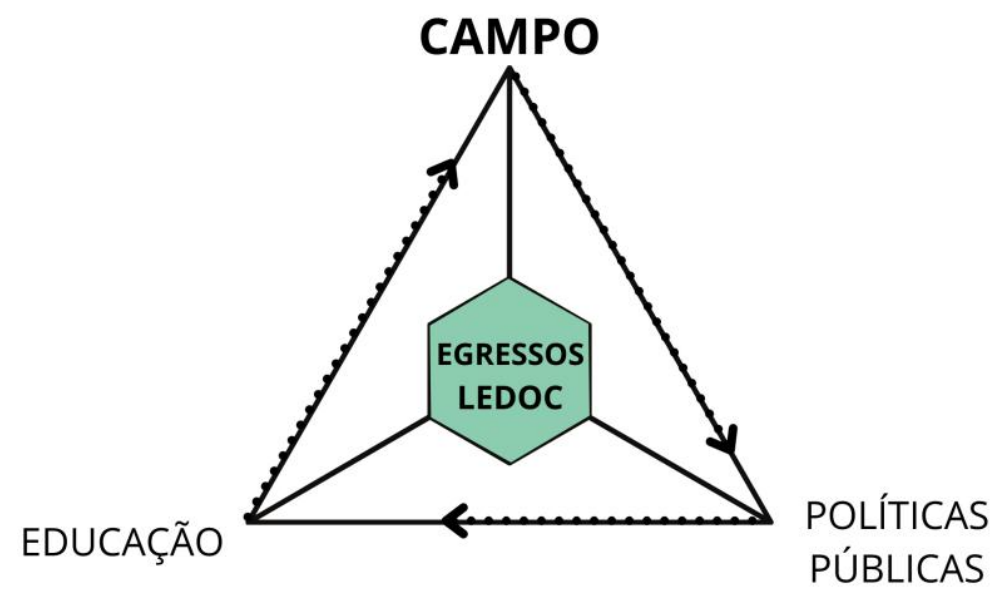


Por isso, para a autora, pensar tais termos em separado significa, na prática, promover uma desconfiguração política e pedagógica de fundo na Educação do Campo. Importante ressaltar que o "Campo", na tríade, aparece em primeira instância: não como uma "ideia" genérica, mas com a materialidade, contradições, conflitos, luta pela terra, pelo trabalho, de sujeitos humanos e sociais concretos. Um campo que, em sua dinâmica histórica, construiu a Educação do Campo (Caldart, 2008, p. 2). A partir dessa tríade, o presente texto se propõe a uma análise da atuação dos egressos da LEDOC/UFRGS, seus desafios e possibilidades para a Educação do Campo em seus territórios. Nesse contexto, apresentamos três movimentos que abordam os elementos inter-relacionados que compõem a tríade, já que, segundo Caldart (2008), em cada um dos termos, os três se manifestam.

\section{O Campo como ponto de partida}

De acordo com Caldart (2008), em relação ao primeiro ponto, a construção de um outro projeto de campo, quando pensada a partir dessa tríade, está associada a uma educação que implique a formação dos trabalhadores para lutas anticapitalistas, necessárias à sua própria sobrevivência: enquanto classe, mas também enquanto humanidade. Formação que inclui novos protagonistas, no caso, os próprios trabalhadores como sujeitos construtores de seu projeto de formação. Os egressos e as egressas fazem parte desse processo e a descrição de seu lugar de moradia e de trabalho evidencia esse reconhecimento:

O lugar onde eu moro é o lugar onde eu nasci. Eu já sou sexta geração que nasce no mesmo sítio, é da família da minha mãe, é um bairro com estrada de chão, tem apenas uma linha de ônibus, são poucos horários, tem uma única escola, não temos posto de saúde e tem uma igreja (Caturrita).

Meu lugar de trabalho é um lugar de ser feliz também. É tranquilo. É no meio da Vida. É onde a vida acontece mesmo, a vida germina a todo o momento aqui. A vida existe aqui a todo o momento. Tem muito bicho, tem as crianças que brincam, tem $o$ entrosamento com as coisas da terra, jogam: bolita, taco, bola (João-deBarro).

Nasci no campo, nasci na zona rural. Tenho uma relação de vida, de família, de sustento, de escola, de trabalho, todas as minhas coisas são relacionadas ao campo (Cardeal).

A concepção e o projeto de vida rural privilegiados, nas políticas públicas que pensam a formação de professores/as no contexto da Educação do Campo, nasce, em sua origem, já tomando posição contrária a projetos alinhados com a lógica neoliberal que veem o campo apenas como meio de exploração. Tal lógica, segundo 
(Caldart, 2008, p. 2), define o campo e os camponeses como um "lugar de negócio, que expulsa as famílias, que não precisa de educação nem de escolas porque precisa cada vez menos de gente" não concebe o "mundo rural" como um espaço de vida, conforme defende Wanderley (2009).

Impossível, neste caso, falar de campo sem abordar, igualmente, as contradições que a ele são inerentes. $\mathrm{O}$ próprio percurso histórico, entrelaçado à luta por uma reforma agrária popular, pelas condições de acesso à educação pública nas comunidades, pelas incontáveis situações de resistência e pelo resguardo de seu território e de suas identidades, fazem da Educação do Campo um conceito em constante movimento. Neste contexto, a fala dos egressos da LEDOC/UFRGS denota um dos objetivos deste movimento, de forma ampla: a construção de um projeto emancipatório de educação, que os permita o protagonismo de se tornarem construtores de seu projeto de formação, a partir da apropriação crítica de suas realidades:

Cresci pensando que o patrão tava certo. A vida foi me mostrando algumas coisas, mas o patrão tinha uma relação e eles têm essa relação de amizade, então eles confundem isso, na cabeça do empregado, né. Precisa sair para poder entender isso. $\mathrm{E}$ aí eu queria que eles também ouvissem esse lado. Eu queria me fazer ouvir com isso. (Cardeal)
[Mudanças pessoais por ter feito curso] mudou tudo. Que nem eu disse, já mudou meu olhar sobre o cara que arrenda as terras lá em casa, eu achava ele a coisa melhor do mundo que tinha aparecido. Mudou minha visão dentro da escola, dentro lá da aldeia, quando o pessoal da Emater chega com as coisas prontas, de cima para baixo. Olha os milho cor-de-rosa. Eles chegaram só alcançaram a semente e o pessoal da aldeia indígena não sabia que aquilo era milho já com veneno para plantar, tavam com fome, cozinharam os milhos e comeram. (Caturrita)

Os pássaros, a partir da LEDOC, passaram a refletir sobre as relações de poder estabelecidas em seus territórios, seja em função das relações de trabalho e do uso da terra, seja ligada às diferenças culturais na produção de alimentos, com a clara diferenciação entre grãos e sementes, na comparação entre indígenas e os demais agricultores atendidos pela Empresa de Assistência Técnica, Extensão Rural e Social do Estado do Rio Grande do Sul (EMATER).

\section{Projeto de Campo, Projeto de país}

No segundo movimento da tríade, que diz respeito às políticas públicas, Caldart (2008) ressalta que os sujeitos que trabalham e vivem no campo não têm sido considerados como produtores de cultura, como protagonistas de seus processos de trabalho e, neste sentido, não têm sido referência para pensar um projeto de 
nação, nem em termos de políticas públicas para educação, nem a outros setores da sociedade. A autora destaca, ainda, que o campo não é qualquer particularidade, nem uma particularidade menor:

Ela diz respeito a uma boa parte da população do país; ela se refere a processos produtivos que são a base de sustentação da vida humana, em qualquer país. Não é possível pensar um projeto de país, de nação, sem pensar um projeto de campo, um lugar social para seus sujeitos concretos, para seus processos produtivos, de trabalho, de cultura, de educação (Caldart, 2008, p. 3).

Neste contexto, as políticas públicas de Estado que sustentam as especificidades formativas da Educação do Campo, não se mantêm isoladas, mas articuladas em um conjunto de ações que dizem respeito tanto ao acesso à terra, à garantia de escolas, o acesso à universidade pública e à soberania alimentar. $\mathrm{Na}$ fala do egresso João-deBarro, abaixo, podemos verificar a importância das políticas públicas que incentivam a produção orgânica de alimentos e a presença da agricultura familiar nas escolas, por exemplo:

Sim, a maior parte, se não me engano 45\% do município todo compra da Agricultura Familiar. Então o mínimo do mínimo que a gente pode utilizar, é o que vem, não é a escola que compra, mas o município. $\mathrm{O}$ máximo eles sempre tentam vir da agricultura familiar, do orgânico (João-de-Barro).
A demanda externalizada por Joãode Barro diz respeito à implementação, pelos municípios, da Lei $n^{\circ} 11.947$, de 16 de junho de 2009, determina que no mínimo 30\% do valor repassado a Estados, Municípios e Distrito Federal pelo Fundo Nacional de Desenvolvimento da Educação (FNDE), para o Programa Nacional de Alimentação Escolar (Pnae), devem ser utilizados obrigatoriamente na compra de gêneros alimentícios provenientes da agricultura familiar. Cabe às ações de formação de professores e professoras na Educação do Campo, portanto, garantir o conhecimento destes programas e das políticas públicas destinadas ao fortalecimento da agroecologia, da agricultura familiar camponesa, do combate à insegurança alimentar e nutricional e da produção orgânica de alimentos, proporcionando, por exemplo, o reconhecimento das feiras de alimentos como um espaço essencialmente educativo na Educação do Campo.

Do mesmo modo, Caldart (2008) enfatiza que a Educação do Campo nasceu a partir da mobilização dos movimentos sociais e da combinação das lutas dos semterra pela implantação de escolas públicas nas áreas de reforma agrária. Ou seja, em termos de políticas de Estado, o acesso à educação pública, gratuita e de qualidade 
para os filhos e filhas da classe trabalhadora foi, desde sempre, pauta das lutas da Educação do Campo. Neste sentido, as LEDOC, garantidas pelo PROCAMPO, fazem parte do caminho histórico trilhado às custas de resistência dos movimentos sociais populares do campo e, também, se incluem em um contexto que busca o acesso e a permanência destes sujeitos na universidade pública. A pedagogia da alternância, adotada nestes cursos, é um pressuposto teórico-metodológico que garante que as pessoas que vivem da terra e de seus ciclos de plantio e colheita, possam estar presentes na universidade ao mesmo tempo que dão continuidade ao trabalho em seus territórios de origem, conforme destaca os egressos Cardeal, João-de-Barro e Caturrita:

Eu sei que eu só pude fazer porque existe alternância, se não existisse alternância eu não teria feito, porque é inviável ir à UFRGS todos os dias. Não tinha como eu fazer isso. Então a alternância me proporcionou isso (Cardeal).

A alternância foi importante para conciliar $\mathrm{o}$ teu trabalho com 0 estudo? ... é essencial para ser feito e pra ti avançar. ... tu precisa desse tempo: 15 dias, 20 dias na comunidade para ver o que realmente está sendo feito, e como aquele conhecimento que é produzido na comunidade se integra ao que tu tá vendo na academia, mas se fosse um curso normal, noturno e durante a semana ia fragmentar muito esse período que tu tem de estudo no local (João-de-Barro).
A possibilidade de ter essa alternância de tempos comunidade e tempos de universidade eu achei que facilitou bastante e fez com que os professores vivenciassem um pouco do nosso dia a dia (Caturrita).

Por fim, outro ponto que consideramos necessário destacar, em termos de políticas públicas voltadas à Educação do Campo, diz respeito à abertura e consolidação de editais de concursos públicos voltados aos egressos e egressas das LEDOC nas redes públicas de ensino. Neste sentido, Brito \& Molina (2016, p. 1723) ressaltam que, como todo curso novo e com um projeto audacioso de modificação das bases epistemológicas, os desafios pautados nas LEDOC vão desde o reconhecimento desses cursos, junto ao Conselho Nacional de Educação (CNE) até a validação junto à sociedade por meio dos concursos públicos. No Rio Grande do Sul, o Conselho Estadual de Educação (CEEDRS) aprovou a Resolução n ${ }^{\circ} 342 / 2018$, que consolida as Diretrizes Curriculares da Educação Básica nas Escolas do Campo, no entanto, a implementação efetiva nos sistemas de ensino ainda não ocorreu, por parte dos órgãos executivos da educação estadual, o que tem limitado o número de concursos públicos que contemplam a formação em Educação do Campo. Em referência a isso, dados dos 43 egressos e 
egressas das três primeiras turmas da

LEDOC/UFRGS, expressos na Figura 5, mostram a inserção destes no mercado de trabalho após a conclusão da graduação:

Figura 5 - A atuação dos egressos da LEDOC/UFRGS campus Porto Alegre.

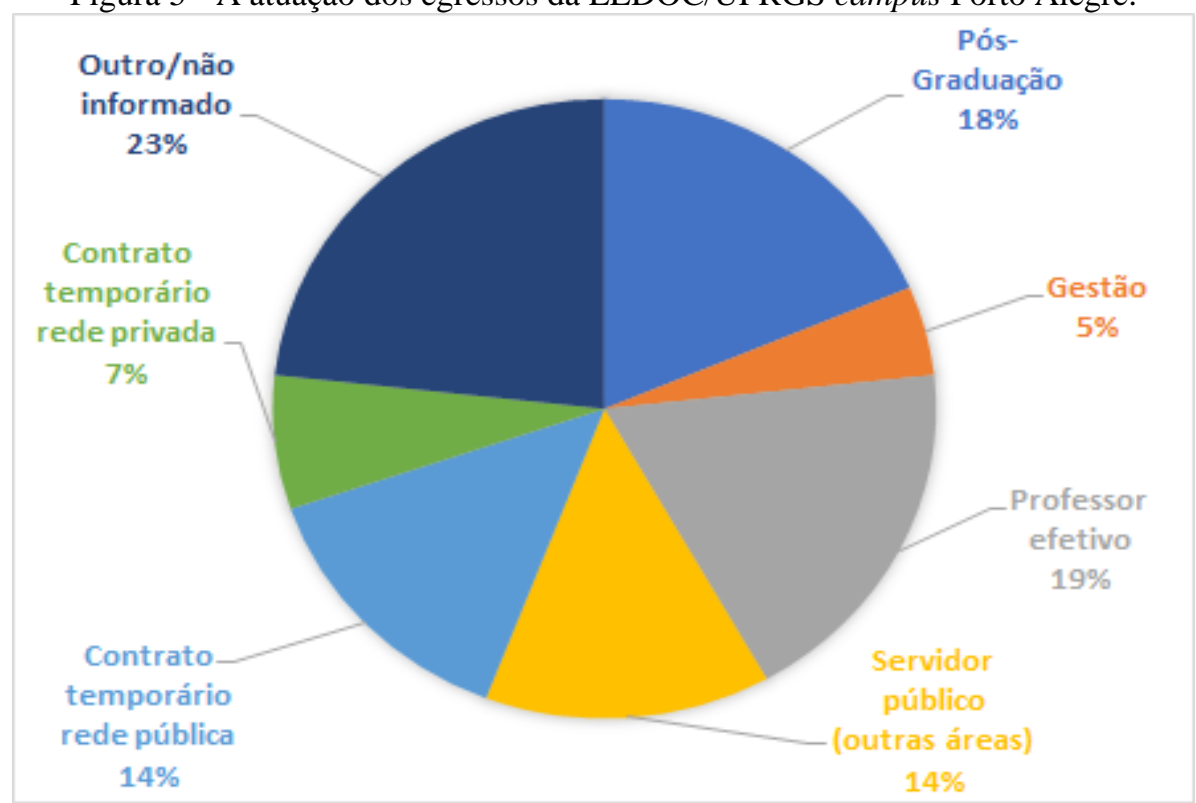

Fonte: Elaborado pelos autores, 2021.

Podemos verificar que, dos 43 egressos e egressas, vários se encontram, atualmente, na pós-graduação em nível de especialização, mestrado e doutorado (18\%), em cargos de gestão (5\%) e nos contratos temporários na rede pública (14\%) e privada (7\%). Do total, 19\% são professores efetivos em redes de ensino, no entanto, essa condição foi alcançada antes da graduação na LEDOC/UFRGS. Igualmente a este último grupo, $14 \%$ dos egressos e egressas são servidores públicos, concursados em outras áreas que não a docência, cargo exercido anteriormente ao curso. Os demais, 23\%, não informaram a ocupação profissional atual, o que inclui o trabalho em outras ocupações na iniciativa privada, a situação de desempregado e a de aposentado.

\section{A Educação do Campo em movimento}

Em relação ao terceiro movimento, a educação, Caldart (2008, p. 4) pontua que o movimento da Educação do Campo "se constitui de três momentos que são distintos, mas simultâneos e que se complementam na configuração do seu conceito, do que ela é, está sendo, poderá ser". Neste sentido, considerando que, neste movimento inacabado e constante se encontram os sujeitos sócio-históricos que dela fazem parte, há vários fatores que 
podemos analisar a partir das falas dos egressos e egressas da LEDOC/UFRGS. Um deles diz respeito ao acesso à universidade pública, algo antes inimaginável a grande parte da população brasileira, e que foi proporcionado devido ao fomento das políticas públicas para o campo e com a interiorização das universidades através da ampliação do acesso ao ensino superior com o Programa de Apoio a Planos de Reestruturação e Expansão das Universidades Federais (Reuni). Na fala de Caturrita, abaixo, podemos compreender o quanto o ingresso na LEDOC muda a perspectiva de futuro não só do estudante que acessa a Universidade, mas de toda a comunidade onde este está inserido:

A minha relação profissional com o campo aconteceu quando eu ingressei no vestibular de Educação do campo, que eu não sabia que era possível trabalhar o que eu aprendi com meu vô, com meu pai, com a minha mãe, que podia abordar esses temas e conversar sobre, dentro de uma universidade (Caturrita).

Este reconhecimento dos saberes próprios do território como algo importante e necessário à formação acadêmica é algo que vem sendo destacado pelas pesquisas como fundamental ao diálogo entre conhecimentos tradicionais e científicos. Na Educação do Campo e, em especial, na formação de professores e professoras de ciências nesse contexto, promover este tipo de trocas e a desmistificação da ciência como algo neutro e acabado, se faz, também, como compromisso histórico com conhecimentos que são comumente negligenciados, como aqueles advindos das comunidades tradicionais. Nestes termos, vários autores e autoras da área da Educação em Ciências (Auler, 2021; Kato, Sandron \& Hoffmann, 2021; Hoffmann \& Schirmer, 2020; Pupo, 2018) vêm buscando no arcabouço teórico da Memória Biocultural (Toledo \& BarreraBassols, 2015), argumentos que embasam a importância, por exemplo, da valorização das sabedorias ecológicas tradicionais como uma "dimensão importante para que a humanidade chegasse onde chegou" (Auler, 2021, p.19). Neste contexto, as falas a seguir demonstram o quanto a formação na LEDOC proporciona este tipo de reflexão:

A lagoa muda de cor, aí ela muda porque fica prateada, porque ela fica azul, porque ela fica verde. ... Do pescador que é a pessoa mais humilde, sabia falar sobre isso, foi a primeira vez que eu levei dentro da escola alguém de fora, foi um pescador falar, foi a esposa do pescador (Cardeal).

Eu sabia que o meu pai sabia, sabia que o peão da fazenda sabia, sabia que o João sabe muito mais do que tu, do que eu, do que todo mundo aqui sobre cavalo, mas eu não sabia que isso era muito importante (Cardeal). 
Saberes populares tradicionais eu aprendi que a gente tem que ter todo um cuidado e tem que preservar um pouco não que não se fale sobre isso, mas preservar na questão assim de não invadir o espaço, entendeu, de ter toda uma questão da licença, de ter toda a questão do se eu posso fazer, eu aprendi muito com o curso junto com o pessoal da aldeia indígena que se organiza primeiro diálogo para depois ver o que vai ser feito, o que não vai ser feito, quais são as permissões é importante a gente ter 0 diálogo com os povos tradicionais (Caturrita).

Neste sentido, a alternância proporcionada pelos Tempos Comunidade e Tempos Universidade na LEDOC é ponto crucial para que estes diálogos de conhecimento ocorram. Kato, Sandron e Hoffmann (2021) enfatizam que estes diálogos interculturais requerem tempo, esforços, imersões e profundas reflexões, e, neste sentido, a Alternância deve articular ensino-pesquisa-extensão para que seja efetiva e se basear nos preceitos da Educação do Campo. Desta maneira, o percurso formativo das LEDOC nas universidades, além de articular os tempos alternados previstos no currículo dos cursos, deve também buscar o fortalecimento em outros espaços formativos, como a pesquisa e a extensão, consolidando assim, o processo de permanência destes cursos nas instituições e nas comunidades. Esta articulação e seus reflexos na formação dos egressos e egressas, ficam explícitos nos trechos a seguir:

Que não é só na escola que acontece [o processo educativo], que era para a gente ir nas famílias. $\mathrm{E}$ isso foi uma das coisas que nos ajudou muito aqui na minha escola né. Porque quando as minhas colegas também entenderam que a gente precisa conhecer as famílias; o que produzem, e como vivem, a gente começou a ter um olhar diferenciado e aproveitar isso para as nossas aulas. Então, o curso me ensinou isso (Joãode-Barro).

Eu havia trazido o campo pra dentro, eu tinha trazido eles pra dentro [referindo-se à universidade]. E isso aconteceu em alguns momentos e que foram claros da autoestima deles, os guasqueiros, quando chegaram na UFRGS, mesmo que brincando, mesmo que tirando a fotografia, colocando no Facebook, eles disseram: como assim que eu nunca ia vim na UFRGS? (Cardeal).

Do mesmo modo, as falas dos entrevistados e entrevistadas apontam tanto os limites quanto possibilidades que a formação por área de conhecimento, na LEDOC, proporciona tanto aos estudantes, quanto aos docentes do curso. Em relação aos docentes, Brick et al. (2014) destacam que, de uma maneira geral, a dificuldade de promover a formação por área de conhecimento nas Licenciaturas em Educação do Campo não tem sido encontrada só na área de Ciências Naturais, mas sim, consiste num desafio histórico da LEDOC, tendo inclusive esta questão das 
áreas de formação se tornado, em muitas instituições, o principal debate entre os educadores que nelas atuam. No entanto, os mesmos autores enfatizam que a formação por área de conhecimento na LEDOC "consiste em um meio, parte de uma estratégia, e não um fim em si mesma" (Brick et al., 2014, p. 17).

Segundo os autores:

A formação por área de conhecimento objetiva contribuir com a transformação dos Planos de Estudos dos cursos, possibilitando novas estratégias de seleção de conteúdos, aproximando-os tanto quanto possível da realidade, bem como objetiva fomentar e promover o trabalho coletivo dos educadores. Estas estratégias devem articular-se à questão maior: a colocação do conhecimento científico a serviço da vida, da transformação das condições de profunda desigualdade e injustiça vigente no campo brasilerio, decorrente da intensificação e agravamento do modelo agrícola hegemonizado pelo agronegócio (Brick et al., 2014, p. 17).

Neste sentido, as falas dos egressos e egressas externalizam os desafios da formação por área e o papel das Ciências da Natureza na compreensão da realidade que, por sua complexidade, é interdisciplinar em sua essência:

Por exemplo: nós fizemos queijo na aula ... Então, todas aquelas relações que tem a partir dali, tanto nos processos de como aquele leite vai virar queijo? Quanto nos processos de quem é que produz queijo aqui na minha comunidade? Como é que ele vende? Fazer todas essas relações, mostrar pras crianças desde a produção, o transporte, a reação química e física que acontece ali; a matemática: o quanto que aquele produtor precisa produzir para realmente ser rentável, ou não é rentável, as dificuldades. O que é aquele alimento? (João-de-Barro).

Porque é real, é dia a dia, é o teu frio, o teu calor, vai aquecer a comida, não vai aquecer a comida. Só que a gente não vê os conceitos de ciências nessas coisas, se habituou a botar as Ciências do livro e as ciências não é do livro (Cardeal).

Hoje eu vejo que [a interdisciplinaridade] é bem mais... não precisa chamar só o professor de outra disciplina para acontecer tu pode trabalhar isso com outros espaços no entorno da Comunidade, como por exemplo, nos meus estágios, eu trabalhei bastante com o pessoal do posto de saúde, isso era uma atividade que envolve a outras disciplinas. Trabalhei com o pessoal da colônia dos pescadores, na aldeia indígena, trabalhei com as lideranças que envolvem questões de cura que é a Pajé, então eu consegui ver que não é só tu convidar um colega para trabalhar e fazer um projeto é muito além (Caturrita).

Dessa maneira, concordamos com Caldart (2008), quando esta se refere que o conhecimento é direito e é necessário, mas que é falsa esta centralidade quando ele é descolado de outras dimensões de um processo formativo; quando se separa conhecimento de valores e de interesses sociais. Sendo assim, é preciso que se problematize e estude a formação por área de conhecimento nas LEDOC, porém, 
pensando qual o papel das Ciências da Natureza neste processo de desvelamento da realidade a partir desta proposta de curso de graduação. Neste sentido, Brick et al. (2014) contribuem ao debate, ao destacarem que cabe às Ciências da Natureza, neste contexto, desenvolver processos que busquem a promoção da superação da fragmentação do conhecimento, criando possibilidades de ampliação da compreensão da realidade pelos educandos do campo.

\section{Os frutos que colhemos das sementes partilhadas}

Ao longo de quatro anos partilhamos com os egressos e egressas, metaforicamente, sementes relacionadas à formação docente na Educação do Campo em Ciências da Natureza. Os pássaros egressos carregaram essas sementes em seus novos voos, agora como educadores e educadoras do campo diplomados na UFRGS. Durante seus novos percursos de vida, em suas comunidades, tais sementes vão cair ao solo e encontrar condições para germinar e produzir novos frutos.

Nesse sentido, as marcas pessoais e profissionais da formação na LEDOC são reais, conforme as falas dos entrevistados. As problematizações conduziram-nos a refletir sobre seu campo, seu lugar de trabalho, de lazer, de cultura, mas, sobretudo de produção de vida nas relações estabelecidas entre as pessoas e seus territórios.

As referidas sementes também produziram frutos nos movimentos de problematizar o currículo, de fortalecer a ideia do campo como um espaço rico, de produção de conhecimento e de vida. Cardeal ao refletir sobre o currículo de sua escola entendeu que era "uma escola do campo com a fala da cidade" e que o contexto vivido deveria ser o ponto de partida do currículo escolar.

Apesar das dificuldades de inserção no mercado de trabalho, pela falta de efetivação da Resolução 342/2018 do Conselho Estadual de Educação do RS, em função da conjuntura, bem como o necessário alinhamento dessa política com os sistemas municipais de ensino, o percentual de egressos com atuação na área da educação merece destaque, pois $77 \%$ estão trabalhando ou cursando pósgraduação, nos diferentes níveis. Os pássaros egressos e egressas seguem espalhando sementes e produzindo novos frutos em seus voos pelos campos.

\section{Referências}

Almeida, J. S. M., Faleiro, W., \& Santos, W. B. (2021). Egressos da Educação do Campo nas Ciências da Natureza: perfil socioeconômico. Revista Brasileira De Educação Do Campo, 6, e6297. http://dx.doi.org/10.20873/uft.rbec.e7750 
Angelo, A. A (2019). Um estudo sobre a prática político-social de egressos da Licenciatura em Educação do Campo da FaE/UFMG: possibilidades e desafios para a formação de educadores do campo (Tese Doutorado). Universidade de São Paulo, São Paulo.

Arroyo, M. G., Caldart, R. S., \& Molina, M. C. (2011). Por uma educação do campo. Petrópolis, RJ: Vozes.

Auler, D. (2021). Freire, Fermento Entre os Oprimidos: Continua Sendo?. Revista Brasileira De Pesquisa Em Educação Em Ciências, e33706, 1https://doi.org/10.28976/1984-

2686rbpec2021u801830

Brick, E. M., Pernambuco, M. M., Silva, A. F. G., \& Delizoicov, D. (2014). Paulo Freire: interfaces entre Ensino de Ciências Naturais e Educação do Campo. In M. C. Molina (Org.). Licenciaturas em Educação do Campo e o ensino de Ciências Naturais: desafios à promoção do trabalho docente interdisciplinar (pp. 23-60). MDA.

Brito, M. M. B. (2017). Formação de professores na perspectiva da epistemologia da práxis: análise da atuação dos egressos do curso de Licenciatura em Educação do Campo da Universidade de Brasília (Tese Doutorado). Universidade de Brasília, Brasília.

Brito, M. M. B., \& Molina, M. C. (2016). Estudo com egressos da licenciatura em Educação do Campo da UnB no contexto da expansão da educação superior. In Anais do XXIV Seminário Nacional UNIVERSITAS/BR. 1723-1746. MaringáPR. Recuperado de: http://www.ppe.uem.br/xxivuniversitas/ana is/trabalhos/e_7/7-012.pdf
Caldart, R. S. (2008). Sobre Educação do Campo. In: Santos, C. A. (Org.). Educação do Campo: campo - políticas públicas educação (pp. 67-86). Brasília: NEAD. Coleção Por Uma Educação do Campo, v. 7.

Constituição da República Federativa do Brasil. (1988, 05 de outubro). Recuperado de:

http://www.planalto.gov.br/ccivil_03/const ituicao/constituicao.htm

Dalmolin, A. M. T. (2020). À sombra deste Jacarandá: articulações entre Ciências da Natureza e Educação do Campo na formação docente (Tese Doutorado). Universidade Federal do Rio Grande do Sul, Porto Alegre. Recuperado de: https://lume.ufrgs.br/handle/10183/210812 \#

Dalmolin, A. M. T., \& Garcia, R. N. (2020). Licenciaturas em Educação do Campo da área de Ciências da Natureza: análise da produção em periódicos nacionais. Revista Brasileira De Educação Do Campo, 5, e6455. http://dx.doi.org/10.20873/uft.rbec.e6455

Decreto $\mathrm{N}^{0} 7.352$, de 04 de novembro de 2010. (2010, 04 de novembro). Dispõe sobre a política de educação do campo e o Programa Nacional de Educação na Reforma Agrária - PRONERA. Recuperado de: http://www.planalto.gov.br/ccivil_03/_ato2 007-2010/2010/decreto/d7352.htm

Fernandes, B. M., Cerioli, P. R., \& Caldart, R. S. (2004). "Primeira Conferência Nacional 'Por uma educação básica do campo': texto preparatório". In Arroyo, M. G., Caldart, R. S., \& Molina, M. C. (Orgs.). Por uma educação do campo (p. 15-30). Petrópolis, RJ: Vozes.

Fernandes, B. M., \& Tarlau, R. (2017). Razões para mudar o mundo: a Educação do Campo e a contribuição do PRONERA. 
Educação \& Sociedade [online], 38(140), 545-567. https://doi.org/10.1590/ES0101$\underline{73302017180679}$

Freire, P. (1995). À sombra desta mangueira. São Paulo, SP: Olho d'água.

Hoffmann, M. B., \& Schirmer, S. B. (2020). Memória biocultural e licenciatura em educação do campo: diálogo necessário para resistência e esperança. In Anais do XIII Seminário Internacional Diálogos com Paulo Freire. Bento Gonçalves, RS: Zolli. Recuperado de:

https://www.ufrgs.br/semeia/wpcontent/uploads/2020/07/Seminariofreire_memoria-biocultural.pdf

Kato, D. S., Sandron, D. C., \& Hoffmann, M. B. (2021). Diálogos Interculturais entre Conhecimentos Tradicionais e Conhecimentos Científicos em uma Comunidade Geraizeira: um Olhar Freiriano na Licenciatura em Educação do Campo. Revista Brasileira De Pesquisa Em Educação Em Ciências, e33693, 1-27. https://doi.org/10.28976/19842686rbpec2021u11291155

Lei $\mathrm{n}^{0}$ 11.947, de 16 de junho de 2009. (2009, 16 de junho). Dispõe sobre o atendimento da alimentação escolar e do Programa Dinheiro Direto na Escola aos alunos da Educação Básica e outras providências. Recuperado de: http://www.planalto.gov.br/ccivil_03/_ato2 007-2010/2009/lei/111947.htm

Melzer, E. E. M., Brick, E. M., \& Hoffmann, M. B. (2021). Os Desafios e potencialidades da área de Ciências da Natureza nas licenciaturas em Educação do Campo (LEDOC) do Sul do Brasil. Revista Da FAEEBA - Educação E Contemporaneidade, 30(61), 178-192.

Molina, M. C. (2017a). Contribuições das Licenciaturas em Educação do Campo para as políticas de formação de educadores. Educação \& Sociedade, 38(140), 587-609. http://dx.doi.org/10.1590/es0101$\underline{73302017181170}$

Molina, M. C. (Org.). (2017b). Licenciaturas em Educação do Campo e o ensino de Ciências Naturais: desafios à promoção do trabalho docente interdisciplinar. Volume II. Brasília, DF: Editora UNB.

Molina, M. C., \& Pereira, M. F. R. (2021). Atuação de egressos(as) das licenciaturas em Educação do Campo: reflexões sobre a práxis. Revista Da FAEEBA - Educação E Contemporaneidade, 30(61), 138-159.

Moraes, R., \& Galiazzi, M. C. (2016). Análise Textual Discursiva. Ijuí, RS: Unijuí.

Pupo, M. A. V. (2018). Por uma Ciência popular da vida: ancestralidade e agroecologia na formulação das Ciências da Natureza da Educação do Campo. Revista Brasileira Educação Campo, 3(3), 862-890.

https://doi.org/10.20873/uft.25254863.2018v3n3p862

Resolução No 342, de 11 de abril de 2018. (2018, 11 de abril). Conselho Estadual de Educação do Rio Grande do Sul. CEEDRS. Consolida as Diretrizes Curriculares da Educação Básica nas Escolas do Campo e estabelece condições para a sua oferta no Sistema Estadual de Ensino. Porto Alegre, 2018b. Recuperado de: http://www.ceed.rs.gov.br/conteudo/21414 /resolucao-n\%c2\%ba-0342-2018

Silva, M. C. L. (2017). Caminhos da interdisciplinaridade: da formação por área de conhecimento à prática educativa de egressos da licenciatura em educação do Campo-Procampo/IFPA, Campus de Castanhal, PA (Tese de Doutorado). Universidade Federal do Ceará, Fortaleza.

Souza, M. A. (2020). Pesquisa Educacional sobre MST e Educação do Campo no 
Brasil. Educação em Revista [online], 36. https://doi.org/10.1590/0102-4698208881.

Stake, R. (1998) Investigación con estudio de casos. Madrid: Ediciones Morata.

Toledo, V. M., \& Barrera-Bassols, N. (2015). A memória biocultural: a importância ecológica das sabedorias tradicionais. Expressão Popular.

Wanderley, M. N. B. (2009). O mundo rural brasileiro: acesso a bens e serviços e integração campo-cidade. Estud.soc.agric., 17(1), 60-85. Recuperado de: https://revistaesa.com/ojs/index.php/esa/art icle/view/308

\section{Informações do Artigo / Article Information}

Recebido em : 31/10/2021

Aprovado em: 04/11/2021

Publicado em:13/11/2021

Received on October 31th, 2021

Accepted on November 04th, 2021

Published on November, 13th, 2021

Contribuições no Artigo: Os(as) autores(as) foram Os(as) responsáveis por todas as etapas e resultados da pesquisa, a saber: elaboração, análise e interpretação dos dados; escrita e revisão do conteúdo do manuscrito e; aprovação da versão final publicada.

Author Contributions: The author were responsible for the designing, delineating, analyzing and interpreting the data, production of the manuscript, critical revision of the content and approval of the final version published.

Conflitos de Interesse: Os(as) autores(as) declararam não haver nenhum conflito de interesse referente a este artigo.

Conflict of Interest: None reported.

\section{Avaliação do artigo}

Artigo avaliado por pares.

Article Peer Review

Double review.

\section{Agência de Fomento}

Não tem.

Funding

No funding

\section{Como citar este artigo / How to cite this article}

APA

Dalmolin, A. M. T, Hoffmann, M. B. \& Schirmer, S. B. (2021). O voo dos pássaros egressos na Licenciatura em Educação do Campo da UFRGS: desafios e possibilidades na formação de professores de Ciências da Natureza. Rev. Bras. Educ. Camp., 6, e13322. http://dx.doi.org/10.20873/uft.rbec.e13322

ABNT

DALMOLIN, A. M. T.; HOFFMANN, M. B.; SCHIRMER, S. B. O voo dos pássaros egressos na Licenciatura em Educação do Campo da UFRGS: desafios e possibilidades na formação de professores de Ciências da Natureza. Rev. Bras. Educ. Camp., Tocantinópolis, v. 6 , e13322, 2021. http://dx.doi.org/10.20873/uft.rbec.e13322 